\title{
Effect of bismuth hydroxide gel on shiga toxin- producing escherichia coli
}

\begin{abstract}
Shiga toxin-producing Escherichia coli (STEC) are emerging pathogens associated with severe and fatal disease in children as Hemolytic Uremic Syndrome (HUS). These bacteria are shedding with feces of cattle contaminating the environment and would enter the food chain if the slaughter process is not done correctly. The prevention measures and control strategies are the key tools to reduce the transmission of STEC. Oral bismuth hydroxide gel has been widely used as antidiarrheal. In this study, the effects of Bismuth hydroxide gel on culture of STEC O157:H7, 026:H11 and O103:H2 was assayed. To evaluate the effects on the viability of STEC O157:H7, O91:H21 and O26:H11 on glass surfaces, two types of novel Bismuth hydroxide presentations, emulsion spray and aerosol were assayed. STEC strains were cultured in LB broth and Bismuth hydroxide gel (Soubeiran Chobet, S.R.L., City of Buenos Aires, Argentina) was added to each plate. At different times, an aliquote of each culture were plated onto MacConkey agar for colony counts. To evaluate the effects on the viability of STEC O157 and non-O157 strains on glass surfaces, Bismuth hydroxide gel emulsion spray and aerosol was independently sprayed on sterile glass plates previously scattered with STEC 0157:H7, O91:H21 and O26:H11.The effects were determined at different times by swabbing on MacConkey agar plates and counting CFU. In both assays, STEC strains without the addition of bismuth hydroxide gel were used as controls
\end{abstract}

All the STEC strains were affected in their growth after the application of Bismuth hydroxide gel in LB broth. Bismuth spray and aerosol were effective for SETC viability on surfaces although the spray showed more efficiency than the aerosol. Since that contaminated surfaces with STEC represent a risk in the food industry, Bismuth Hydroxide gel in these novel presentations is promising as decontaminant on inert surfaces.

Keywords: shiga toxin, bismuth hydroxide gel, food, hemolytic uremic syndrome, strategies, control, stec o157, stec non-o157
Volume 4 Issue I - 2018

Rocío Colello,Analía Etcheverría, María Julia Ruiz, María Emilia Cáceres, Nora Lía Padola 'Laboratorio de Inmunoquímica y Biotecnología, Centro de Investigación Veterinaria Tandil CONICET- CICPBA,Argentin

Correspondence: Nora Lía Padola-Laboratorio de Inmunoquímica y Biotecnología, Centro de Investigación Veterinaria Tandil-CONICET- CICPBA, Facultad de Ciencias Veterinarias, UNCPBA CIVETAN.

(7000) Tandil, Buenos Aires, Argentina, Tel +54 924944385850 Emailnlpadola@vet.unicen.edu.ar

Received: February 07, 2018 | Published: February 14, 2018
Abbreviations: HUS, hemolytic uremic syndrome; STEC, shiga toxin-producing escherichia coli; GIT, gastrointestinal tract; Stx1, shiga toxin 1; Stx2, shiga toxin 2; LEE, locus of enterocyte effacement; LAA, locus of adhesion and autoaggregation

\section{Introduction}

Shiga toxin-producing Escherichia coli (STEC) are emerging pathogens associated with cases of diarrhea, hemorrhagic colitis and Hemolytic Uremic Syndrome (HUS) mainly in children less than 5 years of age. The systemic damage is produced by Shiga toxins (Stx 1 and Stx2), encoded by stx 1 and stx2 genes, respectively. STEC carry another typical virulence factors as intimin (eae gene governed by locus of enterocyte effacement (LEE) by which it binds intimately to epithelial cells inducing a characteristic histopathological lesion of adherence and effacement of enterocytes. ${ }^{1}$ Strains lacking eae (named as LEE-negative STEC) have been associated with severe disease in human and harbor the Locus of Adhesion and Autoaggregation (LAA). ${ }^{2}$ In this group, the overall genome content, phage location, and combination of potential virulence factors are variable and mainly encoded by genetic mobile elements resulting in horizontal gene transfer.

HUS is characterized by acute renal failure, thrombocytopenia, and microangiopathic hemolytic anemia and is a potentially fatal cause of acute renal failure in children. Regarding serotypes, and due to the importance of serotype $\mathrm{O} 157: \mathrm{H} 7$ in human disease, it is common to divide STEC serogroups in two major categories, $\mathrm{O} 157$ and non-O157. ${ }^{1}$ HUS there has not treatment and use of antimicrobial agents is associated with an increased risk of severe sequelae. Besides, antimicrobial resistance genes have been detected in isolates of STEC $\mathrm{O} 26$ obtained from calves, meat samples and a patient with diarrhea. ${ }^{3}$

Cattle are one of the main reservoirs of STEC, they carry these pathogens into their gastrointestinal tract (GIT), and shed them with feces, contaminating the environment. At slaughter, carcasses can become contaminated due to output of gastrointestinal contents, thus STEC would enter the food chain. ${ }^{4}$ Food or the environment contaminated especially affect the food industry and domestic environment. Because there is no specific treatment against HUS, the prevention measures and control strategies are the key tools to reduce the transmission of STEC. Colloidal bismuth hydroxide gel is a drug that contains no associated radicals such as salicylate, which is responsible for the adverse effects and contraindications of bismuth subsalicylate. Colloidal bismuth hydroxide gel has been used for the treatment of diarrhea as well as against Helicobacter pylori because it is not absorbed and it acts in the intestinal lumen without inhibiting peristalsis. ${ }^{5}$

Currently, Bismuth hydroxide gel has been widely used as antidiarrheal but little is known about its bactericidal activity on the survival of STEC (O157 and non-O157) in vitro and on contaminated abiotic surfaces for its use as a decontaminant. 


\section{Methodology}

\section{Bactericidal activity of bismuth hydroxide gel in vitro}

STEC O157:H7, 026:H11 and O103:H2 were cultured in 10mL of $\mathrm{LB}$ broth for $18 \mathrm{~h}$ at $37^{\circ} \mathrm{C}$, and then diluted to reach a final concentration of $10^{3} \mathrm{CFU} / \mathrm{ml}$. Then, it was added $1 \mathrm{ml}$ of oral bismuth hydroxide gel at final concentration of $4.2 \mathrm{mg} / \mathrm{ml}$ (Soubeiran Chobet, S.R.L, City of Buenos Aires, Argentina). At different times (0, 2, 4, 6h) $100 \mu \mathrm{l}$ of each culture were plated onto MacConkey agar and incubated for $18 \mathrm{~h}$ at $37^{\circ} \mathrm{C}$ for colony counts. STEC strains without the addition of bismuth hydroxide gel were used as controls.

\section{Bactericidal activity of bismuth hydroxide gel on contaminated abiotic surfaces}

Two types of novel Bismuth hydroxide presentations, emulsion spray and aerosol were assayed to evaluate the effects on the viability of STEC O157 and non-O157 strains on glass surfaces. STEC strains (serotypes O157:H7, O91:H21 and O26:H11) were grown in LB broth for $18 \mathrm{~h}$ at $37^{\circ} \mathrm{C}$ and then each strain was scattered on sterile glass plates, for duplicate. Each glass plate was sprayed independently with one of the two presentations of Bismuth hydroxide gel (emulsion spray or aerosol) and the effects were determined at different times ( $4 \mathrm{~h}$ and $24 \mathrm{~h}$ ) by swabbing on MacConkey agar plates incubated for $18 \mathrm{~h}$ at $37^{\circ} \mathrm{C}$ and counting CFU. STEC strains without the addition of bismuth hydroxide gel were used as controls.

\section{Results and discussion}

In food industry the survival of STEC could produce cross contamination and the use of disinfectants will reduce its survival. ${ }^{6}$ In STEC O157:H7, 026:H11 and O103:H2 a significant reduction in colony number during the first $6 \mathrm{~h}$ of incubation with bismuth hydroxide gel was observed while in strains controls the number of colonies significantly increased (Table 1). On glass surfaces, after $4 \mathrm{~h}$ of incubation at room temperature, no growth was observed in plates treated with bismuth hydroxide gel spray, while in those treated with aerosol there was growth only in O91:H21 strain. After 24h, there was no count in any plates treated with both presentations (Table 2). Bismuth hydroxide gel is effective against pathogens as STEC that produce severe disease in children. ${ }^{7}$ The effect of bismuth hydroxide gel has been demonstrated in vitro in STEC O157 decreasing the Stx phage titer ${ }^{7}$ and it has been studied the action direct of protection of colonic mucosa and inactivation of the bacterial factors responsible for producing Stx. ${ }^{8}$ However, there are not studies in STEC non-O157 serotypes O26, O103 and O91. More importantly, in this study, results of bismuth hydroxide gel as promisty effect as disinfectant on abiotic surfaces has been demonstrated. This is important because the disinfection of surfaces in contact with foods can prevent food borne illnesses. Even though, although different disinfectants as organic acids are used to control bacterial contamination in all steps of food production chain, several STEC strains are resistant to them. ${ }^{9}$

Table I Effect of bismuth hydroxide gel on culture of STEC in vitro

\begin{tabular}{lllllllll}
\hline Times & Oh & & 2h & & $\mathbf{4 h}$ & & $\mathbf{6 h}$ \\
\hline Strains & $\begin{array}{l}\text { With } \\
\text { bismuth }\end{array}$ & control & $\begin{array}{l}\text { With } \\
\text { bismuth }\end{array}$ & control & $\begin{array}{l}\text { with } \\
\text { bismuth }\end{array}$ & control & $\begin{array}{l}\text { With } \\
\text { bismuth }\end{array}$ & control \\
\hline STEC O26 & 700 & 700 & 5 & 750 & 20 & uncountable & 47 & uncountable \\
STEC O 103 & 700 & 700 & 23 & 7000 & 27 & uncountable & 30 & uncountable \\
STEC O157 & 310 & 337 & 0 & 1000 & 0 & uncountable & 0 & uncountable \\
\hline
\end{tabular}

STEC: Shiga toxin-producing Escherichia coli

Table 2 Effect of novel presentations of bismuth hydroxide gel on glass surfaces contaminated with STEC

\section{Room}

temperature

\begin{tabular}{lllllll}
\hline & $\mathbf{4 h}$ & $\mathbf{4 h}$ & & $\mathbf{2 4 h}$ & $\mathbf{2 4} \mathbf{H}$ \\
\cline { 2 - 7 } & $\begin{array}{l}\text { Strains } \\
\text { controls }\end{array}$ & $\begin{array}{l}\text { Bismuth } \\
\text { spray }\end{array}$ & $\begin{array}{l}\text { Bismuth } \\
\text { aerosol }\end{array}$ & $\begin{array}{l}\text { Strains } \\
\text { controls }\end{array}$ & $\begin{array}{l}\text { Bismuth } \\
\text { spray }\end{array}$ & $\begin{array}{l}\text { Bismuth } \\
\text { aerosol }\end{array}$ \\
\hline STEC O157 & 120 & 0 & 0 & 2 & 0 & 0 \\
STEC O26 & 140 & 0 & 0 & 6 & 0 & 0 \\
STEC 091 & 190 & 0 & 80 & 0 & 0 & 0
\end{tabular}

Table Abbreviations: STEC: Shiga toxin-producing Escherichia coli.

\section{Conclusion}

All the STEC strains were affected in their growth after the application of Bismuth hydroxide gel in LB broth. Novel bismuth presentations, spray and aerosol, are effective for SETC viability on surfaces although the spray showed more efficiency than the aerosol at $4 \mathrm{~h}$. Since that contaminated surfaces with STEC represent a risk in the food industry, Bismuth Hydroxide gel in these novel presentations is promising as decontaminant on inert surfaces.

\section{Acknowledgements}

Authors thank María R. Ortiz and Vet Guillermo Arroyo from the Laboratorio de Inmunoquímica y Biotecnología (Fac Ciencias Veterinarias-CIVETAN-UNCPBA, Tandil, Buenos Aires, Argentina) for her technical assistance.

\section{Conflict of interest}

The author declares no conflict of interest. 


\section{References}

1. Etcheverría AI, Lucchesi PMA, Kruger A, et al. Escherichia coli in Animals. In: Torres AG, editor. Escherichia coli in the Americas. Switzerland; 2016. 149 p.

2. Montero DA, Velasco J, Del Canto F, et al. Locus of Adhesion and Autoaggregation (LAA), a pathogenicity island present in emerging Shiga Toxin-producing Escherichia coli strains. Scientific Reports. 2017;7:7011.

3. Krüger A, Lucchesi PMA, Sanso AM, et al. Genetic characterization of Shigatoxin-producing Escherichia coli O26: H11 strains isolated from animal, food and clinical samples. Front Cell Infect Microbiol. 2015;5:74.

4. Etcheverría A, Padola NL. Shiga toxin-producing Escherichia coli. Factors involved in virulence and cattle colonization. Virulence. 2013;4:(5):1-7.

5. Oviedo S, Díaz M, Valenzuela ML, et al. Acute Diarrhoea in Children: Determination of duration using a combined bismuth hydroxide gel and oral rehydration solution therapy vs. oral rehydration solution. Children. 2016;3(4):45.
6. Møretrøa E, Heira KR, Moab O, et al. Factors affecting survival of Shigatoxin-producing Escherichia coli on abiotic surfaces. Int J Food Microbiol. 2010;138(1):71-77.

7. Subils T, Casabonne C, Balagué C. The inhibitory effect of colloidal bismuth hydroxide gel on Escherichia coli O157: $\mathrm{H} 7$ and on the activity of Shiga toxins. BMC Research Notes. 2014;7:875.

8. Altinier V, Martín G. Diarrhea Caused by Shiga-Toxigenic Escherichia Coli, other Pathogens and HUS. Effects of Bismuth Hydroxide Gel. Gastroenterol Hepatol Open Access. 2017;6:100178.

9. Beier RC, Franz E, Bono JM, et al. Disinfectant and Antimicrobial Susceptibility Profiles of the Big Six Non-O157 Shiga Toxin-Producing Escherichia coli Strains from Food Animals and Humans. J Food Protect. 2016;79(8):1355-1370. 